hydrolysed, stained in Giemsa and examined with a Zeiss microscope with 'Optovar' to give an initial magnification of 2,500. By this method, the chromosomes in the mycelium of Neurospora tetrasperma, $N$. crassa and $N$. sitophila were revealed. As in the ascus there are seven chromosomes in each species.

The chromosome groups most suitable for counting appear at first glance to be at metaphase, but in reality there are no such stages of mitosis in these nuclei. The chromosomes are arranged in linear series upon a filament (Fig. 1). McGinnis ${ }^{9}$ has previously observed similar nuclei in the basidium of Puccinia graminis. In Neurospora the chromosomes are most easily counted when the filament is coiled within the nuclear membrane.

We have observed the following types of nuclei which we believe to be consecutive stages in mitosis : (1) a network within a spherical membrane; (2) an elongated network free of the membrane; (3) a narrow thread; (4) a thread longitudinally split (Fig. 3) ; (5) two separate daughter threads ; (6) a shortened and thickened filament with distinct chromosomes; (7) a similar filament coiled within a membrane.

Masses of nuclear strands may occur in the lumen of hyphæ and also passing through their transverse septa. The identity of the individual nuclei is lost in the tangle (Fig. 2). In such masses, nuclear components may become interchanged, and hyphæ may become unlike genetically.

A detailed report of this work will be published elsewhere.

This work was made possible by grants from the National Research Council, Ottawa, Canada.

E. S. DowDing

(Mrs. E. S. Keeping)

$$
\text { J. WEIJER }
$$

Departments of Botany and Plant Science,

University of Alberta,

Edmonton, Alberta.

2 Dodge, B. O., J. Agric. Res., 35, 289 (1927).

2 MeClintock, B., Amer. J. Bot., 32, 671 (1954).

${ }^{3}$ Fincham, J. R. S., Ann. Bot., 49, 23 (1949).

4 Singleton, J. R., Amer. J. Bot., 40, 124 (1953).

${ }^{5}$ Robinow, C. F., Canad. J. Microbiol., 3, 771 (1957).

'Robinow, C. F., Canad. J. Microbiol., 3, 791 (1957).

'Bakerspigel, A., Canad. J. Microbiol., 5, 125 (1959).

${ }^{8}$ Bakerspigel, A., Amer. J. Bot., 46, 180 (1959).

- MeGinnis, R. C., Canad. J. Bot., 31, 522 (1953).

\section{Amphiplasty in Ribes}

Several authors have reported that in Ribes nigrum L. (black currant) and $R$. grossularia L. (gooseberry), as in all other Ribes species so far investigated, a pair of satellited chromosomes is constantly present ${ }^{1-3}$. However, in 1957 it was noticed that only one satellite could be seen at metaphase in root tip cells of a black currant $x$ gooseberry hybrid. Two further black currant $x$ gooseberry hybrids have since become available for study and in both of these only one satellite is visible in root tip cells. The presence of two satellited chromosomes in two black currant and two gooseberry varieties (Baldwin and Boskoop Giant black currants, Broom Girl and Green Ocean gooseberries), parents of two of the hybrids mentioned above, has been confirmed. Evidently, in the hybrid, one of the parental satellites disappears. This phenomenon has been described in interspecific hybrids of Crepis by Navashin ${ }^{4}$, who includes this and other chromosome changes due to hybridization under the term amphiplasty ${ }^{4,5}$.

Further work in progress on amphiplasty in Ribes species hybrids will be reported elsewhere.

East Malling Research Station,

E. KEEP

East Malling, Maidstone, Kent.

'Darlington, C. D., J. Pomol., 6, 242 (1927).

${ }^{2}$ Meurman, O., Hereditas, 11, 289 (1928).

3 Zielinski, Q. B., Bot. Gaz., 114, 265 (1953).

4 Navashin, M., Cytologia, 5, 169 (1934).

'Navashin, M., $Z$. indukt Abstamm.-u. VererbLehre, Supp. 2, 1148 (1928).

\section{GENETICS}

\section{A Screening Technique for Photosynthetic Mutants in Unicellular Algæ}

IN conjunction with experiments concerned with the genetics of photosynthesis in the sexually reproducing, unicellular, green alga, Chlamydomonas reinhardi ${ }^{1}$ it became necessary to devise a technique to screen for mutants which were blocked in some phase of their photosynthesis. In the technique to be described here the inability to fix carbon dioxide in the light was taken as a requirement of a non-photosynthetic mutant.

There are forty-two mutants of $C$. reinhardi which cannot grow in the light unless the minimal medium ${ }^{2}$ is supplemented with sodium acetate, and it was considered that certain of these mutants might not be able to fix carbon dioxide in the light. Rather than measuring carbon dioxide fixation individually for each mutant by the usual method ${ }^{3}$ it was possible to assay for their ability to fix carbon dioxide while they were growing in colonies on agar medium contained in Petri dishes.

Petri dishes containing colonies of wild-type and several acetate mutants were inverted over a small watch-glass. Acetic acid $(0 \cdot 1 \mathrm{ml}$. of a $1 \mathrm{~N}$ solution) was pipetted into each watch-glass followed by the addition of $0.3 \mathrm{ml}$. of carbon-14 labelled sodium bicarbonate $(2.5 \mu \mathrm{c} . / \mathrm{ml}$. $)$. The operations were carried out in a hood. After the addition of the sodium bicarbonate the light from two 150-watt reflector floodlights was directed toward the Petri dishes. The light was allowed to remain on for $5 \mathrm{~min}$. during which time a comparable set of colonies was exposed to carbon-14 labelled carbon dioxide in the dark as a control.

At the end of $5 \mathrm{~min}$. the lights were turned off, and the colonies were replicated to filter paper. Each of the filter papers was exposed to the fumes of concentrated hydrochloric acid for $3 \mathrm{~min}$. in order to drive off any unfixed carbon dioxide. Radioautographs were made of the replicated colonies using Kodak No-Screen X-ray film and were developed after exposure for one week. The ability of wild-type or a mutant to fix carbon dioxide was seen by the darkening of the emulsion of the film at a position which coincided with the position of the colony on the filter paper. The controls run in the dark gave negative radioautographs.

In this manner it was possible to screen rapidly the forty-two acetate-requiring mutants of $C$. reinhardi for their ability to fix carbon dioxide. Fig. $1 A$ shows the filter paper replica of colonies of wild-type and seven different acetate mutants. Fig. $1 B$ shows the radioautograph of the colonies. It appears from 